\title{
Predicting Future Changes in Muskegon River Watershed Game Fish Distributions under Future Land Cover Alteration and Climate Change Scenarios
}

\author{
Paul J. Steen \\ U.S. Geological Survey, Great Lakes Science Center, 1451 Green Road, Ann Arbor, Michigan 48105, USA \\ Michael J. WiLEY \\ University of Michigan, School of Natural Resources and Environment, 170 Dana Building, \\ Ann Arbor, Michigan 48109, USA \\ JEFFREY S. SCHAEFFER \\ U.S. Geological Survey, Great Lakes Science Center, 1451 Green Road, Ann Arbor, Michigan 48105, USA
}

\begin{abstract}
Future alterations in land cover and climate are likely to cause substantial changes in the ranges of fish species. Predictive distribution models are an important tool for assessing the probability that these changes will cause increases or decreases in or the extirpation of species. Classification tree models that predict the probability of game fish presence were applied to the streams of the Muskegon River watershed, Michigan. The models were used to study three potential future scenarios: (1) land cover change only, (2) land cover change and a $3^{\circ} \mathrm{C}$ increase in air temperature by 2100 , and (3) land cover change and a $5^{\circ} \mathrm{C}$ increase in air temperature by 2100 . The analysis indicated that the expected change in air temperature and subsequent change in water temperatures would result in the decline of coldwater fish in the Muskegon watershed by the end of the 21 st century while cool- and warmwater species would significantly increase their ranges. The greatest decline detected was a $90 \%$ reduction in the probability that brook trout Salvelinus fontinalis would occur in Bigelow Creek. The greatest increase was a $276 \%$ increase in the probability that northern pike Esox lucius would occur in the Middle Branch River. Changes in land cover are expected to cause large changes in a few fish species, such as walleye Sander vitreus and Chinook salmon Oncorhynchus tshawytscha, but not to drive major changes in species composition. Managers can alter stream environmental conditions to maximize the probability that species will reside in particular stream reaches through application of the classification tree models. Such models represent a good way to predict future changes, as they give quantitative estimates of the $n$-dimensional niches for particular species.
\end{abstract}

Disturbances to the structure and function of an ecosystem have the potential to cause shifts in the ranges of some or all of the species that the ecosystem supports. Such disturbances can be the result of natural ecosystem and atmospheric functions, such as fire and flooding, but are often the result of human activity. In a stream ecosystem, pollution, dams, sedimentation, and changes in flow regime, among many other stressors caused by humans, alter the habitat and water quality and change what fish species are able to live in them. Land cover change and global climactic change are two such stresses that researchers anticipate will cause large range shifts in stream fish.

While it is likely that future shifts in species' ranges will be the result of both climate change and land cover alteration, few studies have evaluated how both factors

* Corresponding author: psteen@hrwc.org

Received January 16, 2009; accepted October 12, 2009 Published online January 14, 2010 would operate simultaneously. We examined how the presence of nine game fishes in the streams of the Muskegon River watershed, Michigan, would change in the 21 st century as a result of changes in both land cover and stream temperature. We also used the model predictions to evaluate how habitat conditions can be altered to maximize the probability of game species residing in particular stream reaches. The nine species were chosen because of their high importance to residents and scientists enjoying and studying the Muskegon River watershed; a small number of species was selected so that each one could be examined closely rather than giving a general overview of the entire fish community.

Human land use has constantly intensified from the presettlement era to present, and land cover shifts over the next century will undoubtedly continue to have effects on aquatic fauna. We hypothesized that future urban growth would reduce the prevalence of game fishes throughout the Muskegon River watershed. The physical impacts of urbanization on streams have been 
extensively studied (Klein 1979; Booth and Jackson 1997; Walsh et al. 2005), and many studies have shown that physical changes have consequences for a stream's biota. Authors have reported a negative association between urbanization and fish abundance, richness, and the number of intolerant fish species (Scott et al. 1986; Weaver and Garman 1994; Tabit and Johnson 2002; Wang et al. 2003a; Miltner et al. 2004; Morgan and Cushman 2005). Some of these studies have shown that there are threshold effects, which is relevant because this study uses threshold-driven classification tree models. Snyder et al. (2003) reported that sites with poor indices of biotic integrity for fish had more than 7\% urban land in the stream's catchment. Wang et al. (2001) found that small increases in imperviousness above an $8-12 \%$ threshold could result in major changes in stream condition.

Alternatively, we hypothesized that the negative impacts on fish would be mitigated somewhat by the expected reduction of agricultural land in the Muskegon River watershed (Pijanowski et al. 2002a). Studies have shown that agriculture has negative effects on some species of fish (Wang et al. 2003b; Zimmerman et al. 2003; Barker et al. 2006); for example, Talmage et al. (2002) reported that fish communities suffered with increases in the quantity of silt, a substrate that is associated with agricultural land. However, there seems to be agreement in the literature that the effect of agriculture on fish is not as clear and straightforward as that of urbanization.

In addition, we expect that natural land cover (such as forests, which increase hydrologic stability, provide in-stream habitat, and which will probably continue to replace old agricultural fields in the Muskegon River watershed; Pijanowski et al. 2002a, 2002b, 2005) will mitigate some of the negative urban and agricultural effects (Talmage et al. 2002; Meador and Goldstein 2003; Roy et al. 2006; Barker et al. 2006).

It is anticipated that climate change will also have major effects on the future of fish. Global warming will increase water temperatures, alter precipitation patterns, and increase evaporation (Regier and Meisner 1990; Schindler 2001). Several studies have predicted that increases in water temperature due to climate change will reduce the available habitat for brook trout, brown trout Salmon trutta, and other coldwater species. Meisner (1990) predicted $40 \%$ reductions in trout habitat in southern Ontario streams, Flebbe (2006) predicted 53-97\% reductions in such habitat in the southern Appalachian Mountains, and Jager et al. (1999) predicted that climate change would restrict brown trout and rainbow trout Oncorhynchus mykiss to higher elevations in Sierra Nevada streams. Eaton and Scheller (1996), using models based solely on thermal habitat, predicted that global warming of $4^{\circ} \mathrm{C}$ would reduce the number of cold- and coolwater fish across the United States by $50 \%$. Higher water temperatures due to climate change are projected to reduce the number of U.S. lakes able to hold cold- and coolwater fish communities by $45 \%$ and $30 \%$, respectively (Stefan et al. 2001). We hypothesized that the results of our models would be consistent with those of past studies in showing large decreases in the potential habitat for coldwater species. At the same time, we hypothesized that warmwater fish would gain habitat as former coldwater streams become warm enough to support them.

We believe that it is important to anticipate future changes in fish prevalence and ranges. Predictions of such changes can enable managers to prevent economic hardship by altering stocking policies, size or harvest limits, and fishing seasons; allow conservation groups to identify and acquire areas with a high risk of habitat degradation; and create public awareness of the importance of land use decisions and management practices. Models of fish community changes can help quantify the attendant risks by indicating what environmental conditions should be managed to maximize fish potential as well as inform the decision-making processes.

In addition to examining how future changes to fish species will result from both climate change and land cover alteration, we discuss the suitability of using classification trees for making this type of prediction. Classification trees are being used more often in ecology studies (Steen et al. 2008), and a justification for using them in habitat and species range studies is given.

\section{Methods}

Study units. - This modeling effort represents a part of the Muskegon River Ecological Modeling System (MREMS), a modeling framework capable of predicting future and past states of the Muskegon River system and evaluating likely changes in hydrology, chemistry, and biology (Seelbach and Wiley 2005; Riseng et al. 2006).

The Muskegon River watershed, which is located in the western Lower Peninsula of Michigan, incorporates over $6,000 \mathrm{~km}^{2}$ of land and has a mix of urban, agricultural, forest, and wetland land cover (O'Neal 1997). The Muskegon River system, which is over $2,800 \mathrm{~km}$ in length, drains into Lake Michigan. The water has low concentrations of nutrients and contaminants and has stable flows owing to permeable geology and high groundwater input and thus provides high-quality cool- and coldwater fisheries (O'Neal 1997). 


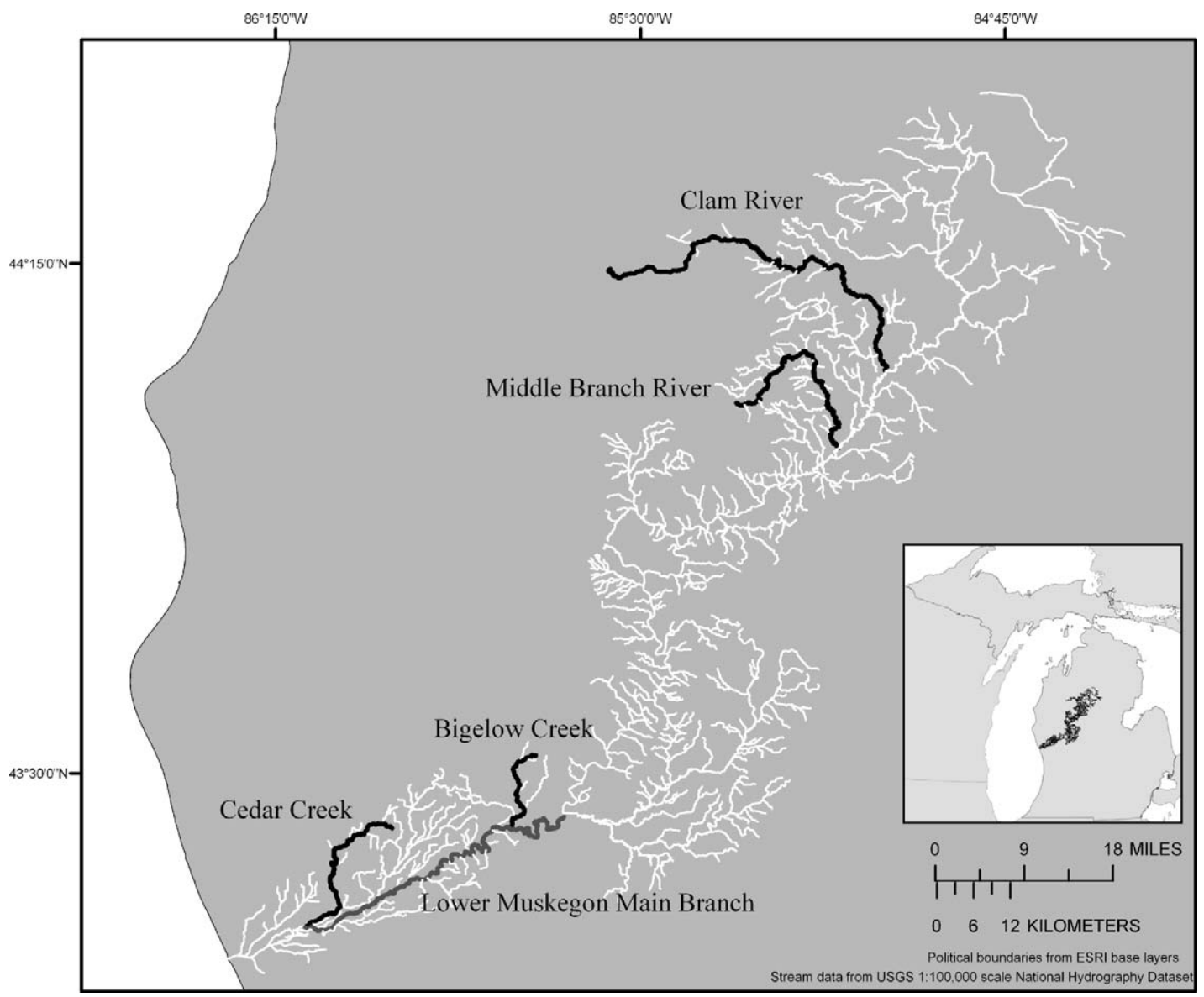

FIGURE 1.-Map of the Muskegon River watershed on which the five stream study units are highlighted.

We focused on five reaches of the Muskegon system that contain important sport fisheries because of their high fish populations and important spawning areas (Figure 1). The main branch of the Muskegon River from Muskegon Lake to Croton Dam is approximately $70 \mathrm{~km}$ long and supports walleye Sander vitreus, smallmouth bass Micropterus dolomieu, northern pike Esox lucius, steelhead (anadromous rainbow trout), brown trout, and the anadromous Chinook salmon Oncorhynchus tshawytscha and coho salmon Oncorhynchus kisutch (O'Neal 1997; Hanchin et al. 2007). Hereafter, mention of the lower Muskegon River refers to this river section, while the Muskegon River system refers to all of the streams in the Muskegon watershed. Bigelow Creek is an $18-\mathrm{km}$ coldwater stream that enters the lower Muskegon River below Croton Dam; it supports a resident brook trout and brown trout population and provides spawning habitat for steelhead and Chinook salmon. Cedar Creek, a 38-km coldwater stream that flows into Muskegon Lake, provides coldwater habitat for brook and brown trout and also supports Chinook salmon. Upstream from Croton Dam, the cold/coolwater Middle Branch River (48 $\mathrm{km}$ long) and Clam River (78 km long) support both brook and brown trout populations. Portions of the Middle Branch and Clam rivers have been designated as blue-ribbon trout streams by the Michigan Department of Natural Resources (MDNR; Trout Unlimited 2008). In addition to focusing on these five specific areas, we did an overview of the whole stream system to quantify the generic changes across the entire watershed.

Model development and application.-Changes in the Muskegon River's game fish species were predicted with classification tree fish distribution models developed for the entire state of Michigan (Steen et al. 2008). These models predicted fish species presence or absence in interconfluence stream reaches from the 1:100,000 National Hydrography Dataset (Brenden et al. 2006; http://nhd.usgs.gov/). The 
TABLE 1.- Habitat and land cover variables used in the creation of presence/absence models for Michigan stream fishes. The values given are for the Muskegon River system in 2001. The variables with asterisks were adjusted in the future scenarios.

\begin{tabular}{|c|c|c|c|c|}
\hline Variable & Description & Minimum & Maximum & Mean \\
\hline Water_Temp* & Water temperature, predicted July mean $\left({ }^{\circ} \mathrm{C}\right)$ & 13.9 & 25.4 & 18.1 \\
\hline Catcharea & Area of the watershed $\left(\mathrm{km}^{2}\right)$ & 0.03 & $6,957.0$ & 482.9 \\
\hline \multicolumn{5}{|l|}{ Connectivity } \\
\hline Pondupst & Distance upstream to closest pond $\geq 5$ acres $^{\mathrm{a}}(\mathrm{m})$ & 0 & 38,533 & 5,635 \\
\hline Ponddnst & Distance downstream to closest pond $\geq 10$ acres $^{\mathrm{a}}$ or Great Lake (m) & 0 & 228,594 & 58,572 \\
\hline Linkdcatch & $\begin{array}{l}\text { Distance from downstream reach with at least } 10 \% \text { more catchment } \\
\text { area than target reach }(\mathrm{m})\end{array}$ & 0 & 58,850 & 1,685 \\
\hline Down_Length & Distance to Great Lake from downstream end of reach $(\mathrm{m})^{\mathrm{b}}$ & 0 & 84,431 & 36,245 \\
\hline \multicolumn{5}{|c|}{ Geology/Hydrology } \\
\hline Wt_Fine & Fine-grain surficial geology ( $\%$ of watershed) & 0 & 1 & 0.16 \\
\hline Wt_Coarse & Coarse-grain surficial geology (\% of watershed) & 0 & 1 & 0.79 \\
\hline 10_Yield* & $10 \%$ exceedance flow yield $\left(\mathrm{cm} / \mathrm{km}^{2}\right)$ & 0.007 & 0.034 & 0.018 \\
\hline 90_Yield* & $90 \%$ exceedance flow yield $\left(\mathrm{cm} / \mathrm{km}^{2}\right)$ & 0.000 & 0.003 & 0.001 \\
\hline Gradient & Channel gradient & 0.000 & 0.141 & 0.004 \\
\hline 10_Power* & High-flow-based specific power $\left(\mathrm{cm} / \mathrm{km}^{2}\right)$ & 0.000 & 0.026 & 0.001 \\
\hline 90_Power* & Summer-flow-based specific power $\left(\mathrm{cm} / \mathrm{km}^{2}\right)$ & 0.0000 & 0.0083 & 0.0001 \\
\hline \multicolumn{5}{|l|}{ Land cover } \\
\hline Wt_Forest* & Forest cover (\% of watershed) & 0.0 & 94.1 & 41.1 \\
\hline Wt_Wetland* & Wetland cover (\% of watershed) & 0.0 & 99.7 & 15.8 \\
\hline Wt_Agr* & Agricultural land (\% of watershed) & 0.0 & 92.8 & 3.2 \\
\hline Wt_Urban* & Urban land (\% of watershed) & 0.0 & 54.5 & 26.4 \\
\hline Phosphorus* & Total phosphorus, predicted (mg/L) & 0.01 & 0.37 & 0.04 \\
\hline
\end{tabular}

${ }^{\mathrm{a}} 1$ acre $=0.405$ ha.

${ }^{\mathrm{b}}$ Excludes reaches disconnected from the Great Lakes by dams.

species-specific models were built from a suite of landscape-scale habitat data (the independent variables; Table 1) and statewide fish data from the Michigan Rivers Inventory (Seelbach and Wiley 1997), referred to as the training data (the dependent variable). Independent fish data from the MDNR Fish Collection System, referred to as the testing data, were used to obtain a measure of model accuracy. While Steen et al. (2008) developed models for 93 fish species, for the reasons mentioned above only the models for 9 game fish species are used in this study: brook trout, brown trout, Chinook salmon, coho salmon, largemouth bass Micropterus salmoides, northern pike, rainbow trout, smallmouth bass, and walleye.

A short description of the modeling process is given here (Breiman et al. 1984). For each species, the classification tree algorithm used the independent variables to divide the training data into groups so that each group's composition was as pure as possible for the two classes of interest: presence and absence. Although the classification tree algorithm attempted to create groups with very high purity (e.g., $100 \%$ of the observations showing presence), depending on the strength of the relationship between the independent and dependent variables the purity could be low (e.g., $50 \%$ showing presence and 50\% absence). Groups were divided into smaller subgroups when such a division would result in overall higher model purity and an improvement in the predictions of an indepen- dent data set. When further division resulted in poorer prediction of the independent data set, the algorithm stopped the dividing process. Each one of the final groups is called a "terminal node." A classification tree contains several terminal nodes, each of which was formed from a unique combination of independent variables.

In making predictions, an unclassified observation was entered into the top of a tree and followed the model's splitting rules until it was classified into a terminal node (see Figure 2 for an example). Observations falling into a particular terminal node were predicted by the composition of the training observations in the terminal node. That value could either be an absolute classification (e.g., present or absent) or a probability based on the number of presence observations divided by that of total observations.

We used the models to derive a probability, not an absolute classification; that is, for each species in every stream reach in the Muskegon River system, we predicted a probability based on the frequency of species occurrence (FO). For example, stream reaches with a mean July water temperature greater than $19.4^{\circ} \mathrm{C}$ contained brook trout in only 9 of the 276 training observations and 29 of the 234 testing observations (altogether, in 38 of 510 observations [0.08] there were brook trout; Figure 2a). We assumed that the rivers included in the training and testing data were 


\section{a. Brook trout}

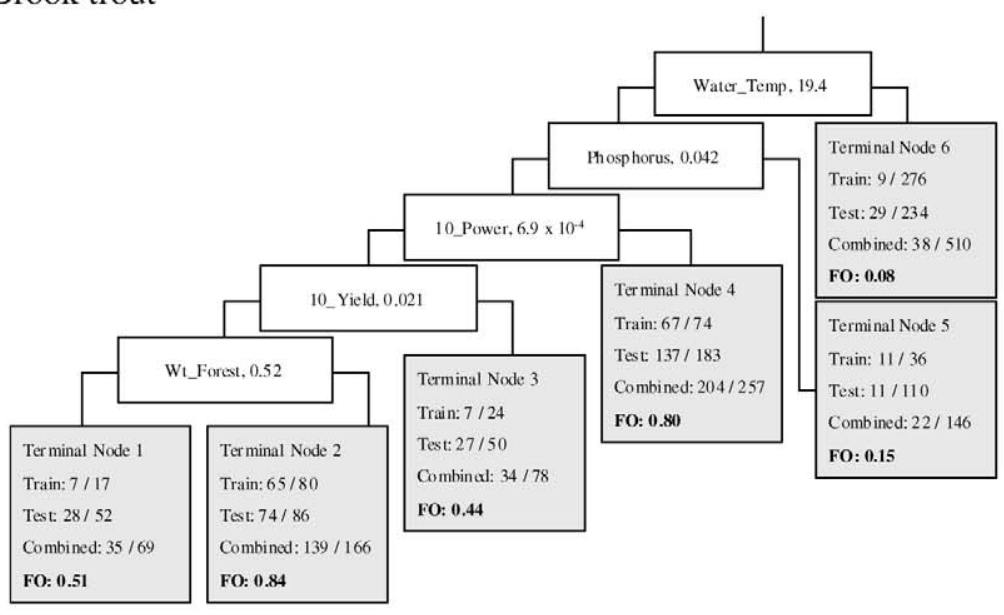

\section{b. Brown trout}

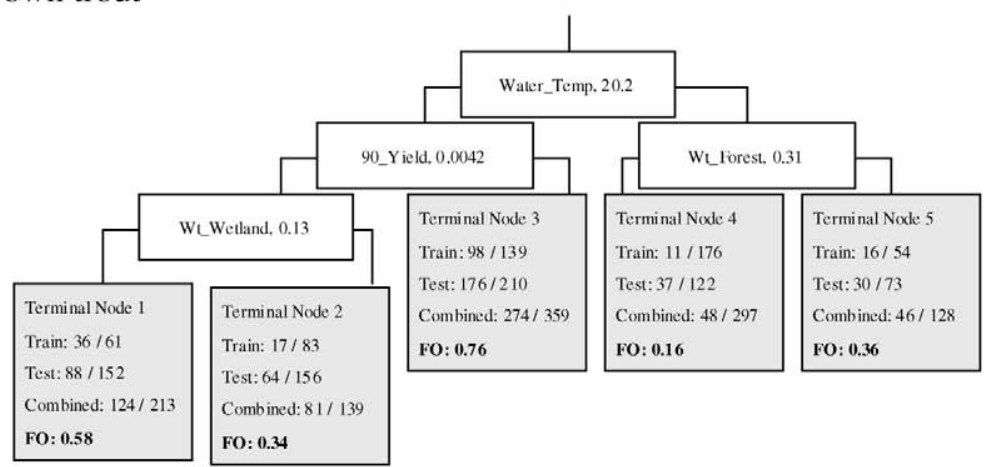

\section{c. Rainbow trout}

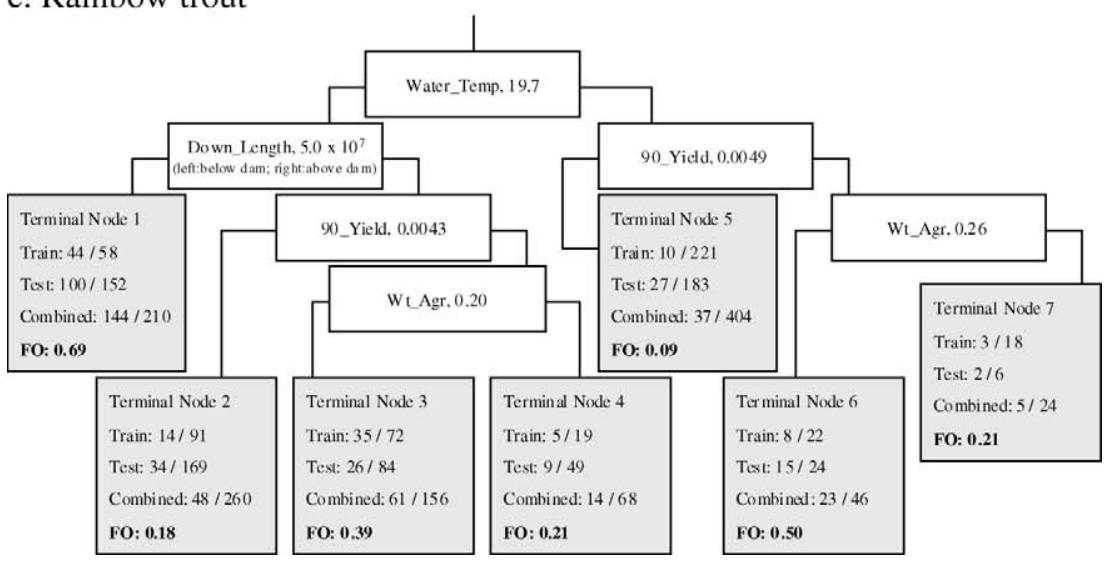

FIGURE 2.-(a)-(i) Classification tree models used to predict fish distributions in the future scenarios. Each white box indicates a variable split (see Table 1 for variables); stream reaches with habitat values less than or equal to the split value are shown to the left, those with habitat values greater than the split value to the right. A terminal node indicates the final classification of a stream reach. The model was created with the training data and validated with the testing data (Steen et al. 2008). The numbers given with the terminal node indicate the number of observed presences out of the total number of observations; the frequency of occurrence (FO) is the proportion of observed presences in the training and testing data combined. 


\section{d. Chinook salmon}

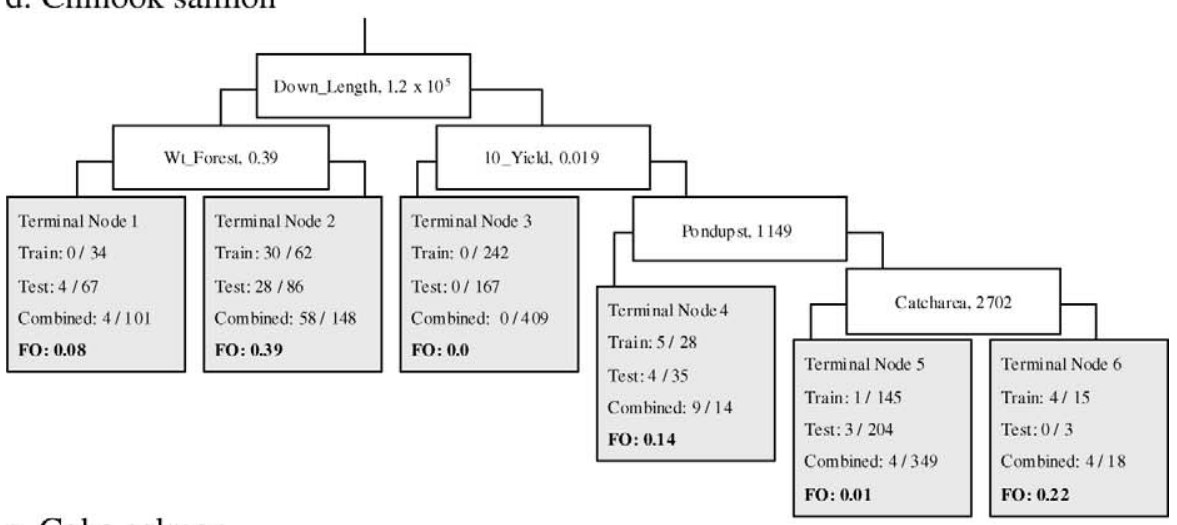

\section{e. Coho salmon}

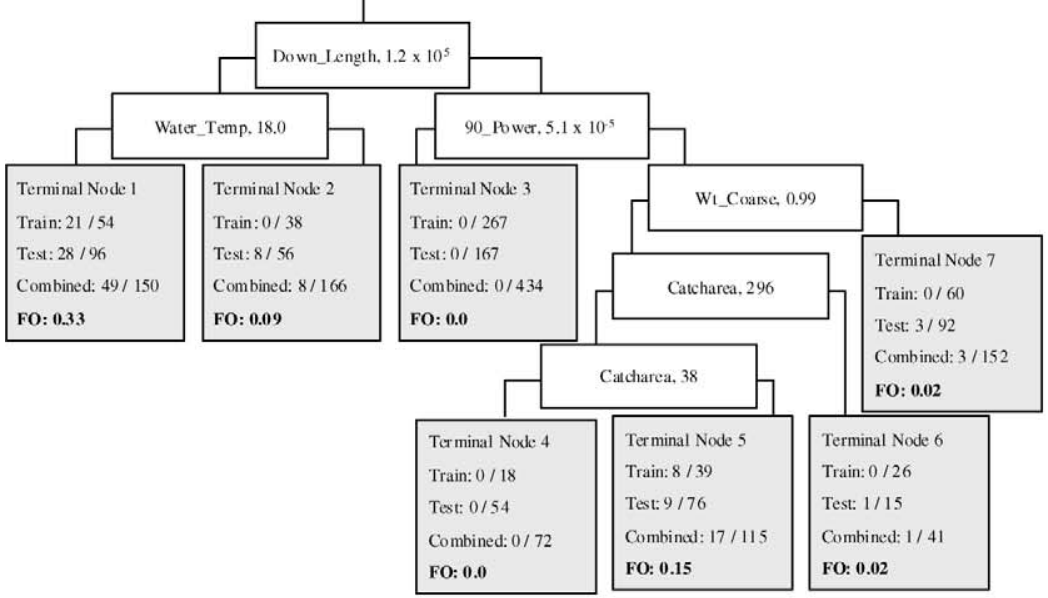

\section{f. Smallmouth bass}

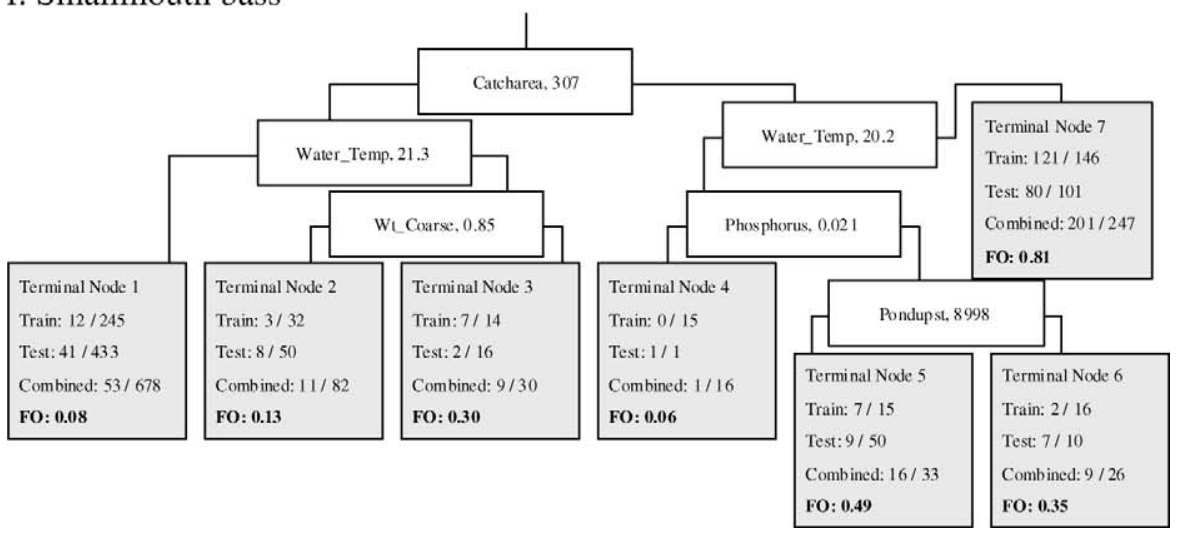

FIGURE 2.-Continued. 


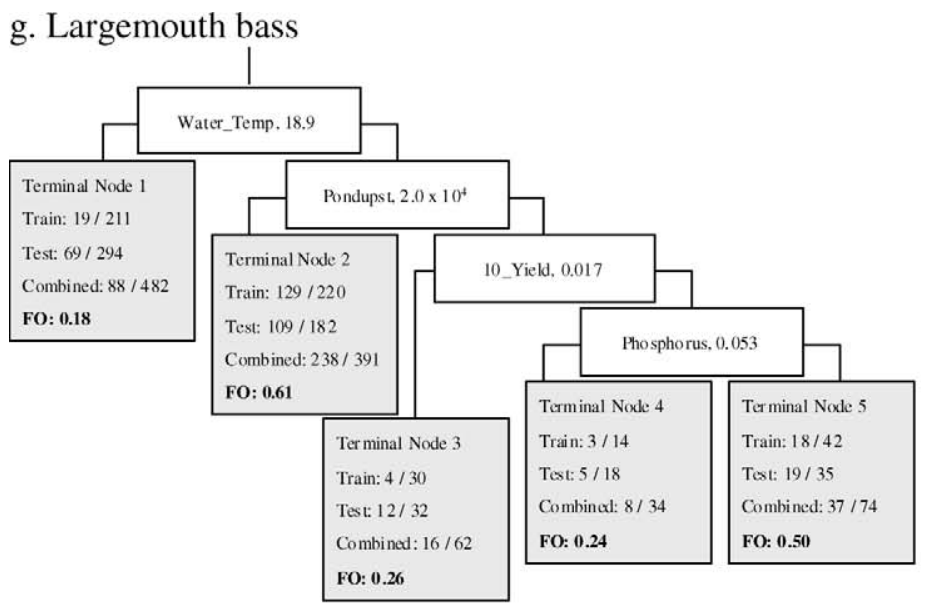

\section{h. Northern pike}

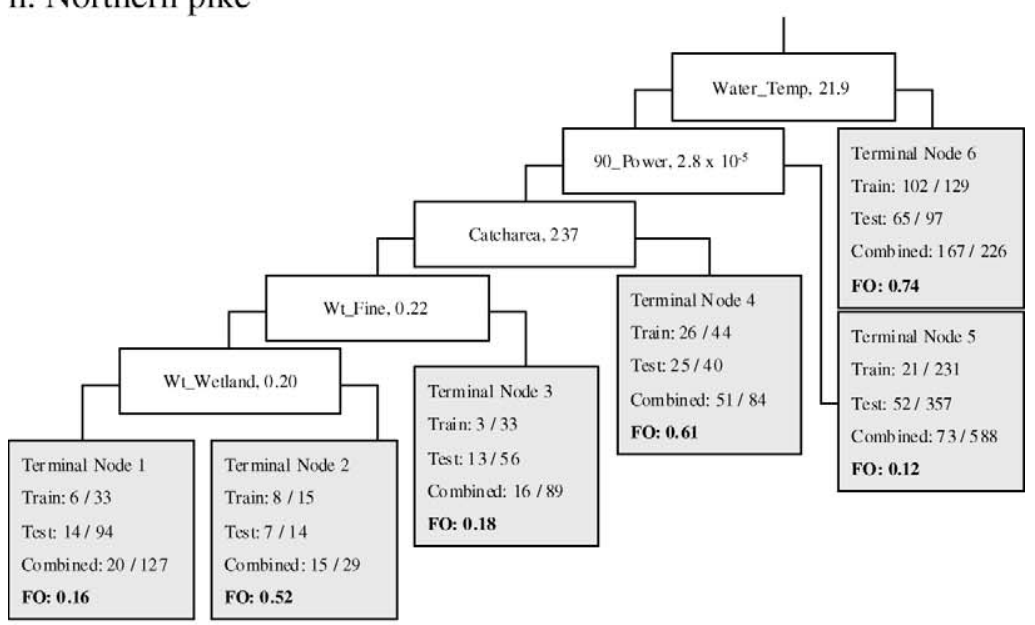

\section{i. Walleye}

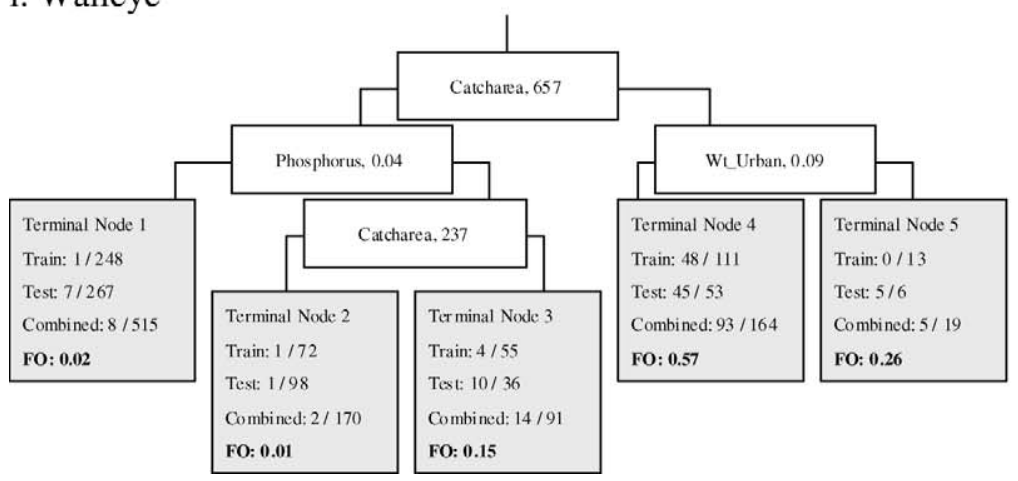

FIGURE 2.-Continued. 
representative of all Michigan streams; therefore, we predicted that in the Muskegon watershed stream reaches with a daily mean July water temperature greater than $19.4^{\circ} \mathrm{C}$ would contain brook trout $8 \%$ of the time. Using this approach was more realistic that using presence/absence because brook trout are occasionally found in streams with a mean July temperature exceeding $19.4^{\circ} \mathrm{C}$. The value 0.08 represented one terminal node in the classification tree; stream reaches with different combinations of habitat values were classified into different terminal nodes with different FOs.

Based on the classification tree models, we assigned an FO to each Muskegon confluence-to-confluence stream reach for each species. However, because our study units were composed of many stream reaches, summary values that averaged the FO values for each unit were needed. To derive them, we took the average FOs for the stream reaches composing each unit (weighted by stream length) and converted them to a percentage, hereafter referred to as the percent chance of occurrence (PO). For example, if Cedar Creek was composed of three stream reaches with lengths of 10 , 11 , and $12 \mathrm{~km}$ and had brown trout FOs of $0.3,0.5$, and 0.8 , respectively, the average PO per stream kilometer for this $33-\mathrm{km}$ reach would be

$$
\begin{aligned}
& (0.3 \cdot 10)+(0.5 \cdot 11)+(0.8 \cdot 12) /(10+11+12) \\
& \quad=0.55, \text { or } 55 \% .
\end{aligned}
$$

According to this interpretation, randomly sampling any $1-\mathrm{km}$ reach in that creek would result in a $55 \%$ chance of finding brown trout.

Forecasting future changes.-We expect to see future changes in the habitat variables on which the classification tree models base their predictions. We developed three potential scenarios for what could happen to those variables in the future. The baseline scenario assumed land cover change without any global warming; future air and water temperatures remain at their 2001 levels, although the land cover and associated hydrology and phosphorus variables change as described below. The second and third scenarios assumed the same changes to land cover but also included either mild or severe global warming. The second and third scenarios were not simulated for walleye and Chinook salmon because the predictive models for those species did not contain the water temperature variable.

Application of the neural-net based land transformation model (Pijanowski et al. 2002a, 2002b, 2005) to the Muskegon watershed produced estimates of urban, agricultural, forest, and wetland land cover for each decade from 2010 to 2040, 2070, and 2100. The predictions were made on $30-\mathrm{m}$ cells in a raster of the Muskegon watershed. This version of the land transformation model was classified as "business as usual" because it assumed a continuation of the average rates of urban and forest growth observed from 1978 to 1998; urban and forest land use is predicted to expand at the expense of agriculture, a pattern that has been observed since the 1920s.

Since the land transformation data were based on aerial photos but the 2001 land cover data used by the fish models were based on satellite images (MCGI 2008), we needed to convert the land transformation model predictions into a format compatible with the 2001 coverage. To do this, we created simple linear regression equations for the years 2001 (satellite images) and 1998 (aerial photos) for each land cover category (urban, agricultural, forest, and wetland) and applied them to the forecasted land cover. The equations are as follows:

(1) satellite urban $=0.003+$ aerial urban $\cdot 0.897$ (adjusted $R^{2}=0.81$ )

(2) satellite agricultural $=0.027+$ aerial agriculture . 0.962 (adjusted $R^{2}=0.93$ )

(3) satellite forest $=0.089+$ aerial forest $\cdot 0.831$ (adjusted $R^{2}=0.69$ )

(4) satellite wetland $=0.088+$ aerial wetland $\cdot 0.687$ (adjusted $R^{2}=0.47$ )

The $90 \%$ and $10 \%$ exceedance flows and stream power were predicted from regressions based on urbanization, agriculture, and surficial geology (Brenden et al. 2006) and were adjusted for each year of the forecasted land cover. Future values of total phosphorus were calculated from a multiple-regression equation based on percent agriculture and flow variables (Steen et al. 2008).

The second future scenario (mild temperature change) added the assumption that the air temperature increases $3^{\circ} \mathrm{C}$ from 2001 to 2100 (approximately $0.03^{\circ} \mathrm{C}$ per year). The third future scenario (severe temperature change) assumed that air temperature increases $5^{\circ} \mathrm{C}$ from 2001 to 2100 (approximately $0.05^{\circ} \mathrm{C}$ per year). These values are used because studies of air temperature change predict an increase of $3-5^{\circ} \mathrm{C}$ by 2100 in the Midwestern United States (National Assessment Synthesis Team 2001). Because of the uncertainty regarding how climate change will alter precipitation and evaporation, we focused on temperature change and did not implement flow changes except for those caused by land cover alteration.

We made the assumption that water temperature will increase by 0.8 times the rate of air temperature 
TABLE 2.-Land cover in 2001 (measured) and 2100 (predicted) for each study unit in the Muskegon River system, along with the associated water temperatures, total phosphorus levels, and $90 \%$ exceedance flow yields.

\begin{tabular}{|c|c|c|c|c|c|c|c|c|c|c|c|c|}
\hline & \multicolumn{2}{|c|}{$\begin{array}{l}\text { Muskegon } \\
\text { system }\end{array}$} & \multicolumn{2}{|c|}{$\begin{array}{c}\text { Lower Muskegon } \\
\text { River }\end{array}$} & \multicolumn{2}{|c|}{$\begin{array}{l}\text { Bigelow } \\
\text { Creek }\end{array}$} & \multicolumn{2}{|c|}{$\begin{array}{l}\text { Cedar } \\
\text { Creek }\end{array}$} & \multicolumn{2}{|c|}{$\begin{array}{l}\text { Clam } \\
\text { River }\end{array}$} & \multicolumn{2}{|c|}{$\begin{array}{c}\text { Middle } \\
\text { Branch River }\end{array}$} \\
\hline & 2001 & 2100 & 2001 & 2100 & 2001 & 2100 & 2001 & 2100 & 2001 & 2100 & 2001 & 2100 \\
\hline$\%$ Urban & 4 & 39 & 3 & 36 & 1 & 68 & 4 & 78 & 4 & 40 & 3 & 29 \\
\hline$\%$ Agriculture & 18 & 3 & 19 & 3 & 6 & 0 & 15 & 0 & 26 & 3 & 27 & 3 \\
\hline$\%$ Forest & 45 & 51 & 45 & 53 & 69 & 28 & 53 & 19 & 40 & 52 & 42 & 65 \\
\hline$\%$ Wetland & 18 & 3 & 18 & 3 & 10 & 0 & 13 & 1 & 14 & 1 & 18 & 1 \\
\hline$\%$ Other & 15 & 4 & 15 & 5 & 14 & 4 & 15 & 2 & 16 & 4 & 10 & 2 \\
\hline \multicolumn{13}{|c|}{ Average water temperature $\left({ }^{\circ} \mathrm{C}\right)$} \\
\hline Mild change scenario & 18.1 & 20.5 & 22.9 & 25.3 & 16.9 & 19.3 & 16.8 & 19.2 & 19.9 & 22.3 & 18.4 & 20.8 \\
\hline Severe change scenario & 18.1 & 22.1 & 22.9 & 26.9 & 16.9 & 20.9 & 16.8 & 20.8 & 19.9 & 23.9 & 18.4 & 22.4 \\
\hline Phosphorus (mg/L) & 0.043 & 0.027 & 0.034 & 0.033 & 0.026 & 0.022 & 0.060 & 0.026 & 0.035 & 0.027 & 0.050 & 0.034 \\
\hline $\begin{array}{l}90 \% \text { exceedance flow } \\
\text { yield }\left(\mathrm{cm} / \mathrm{km}^{2}\right)\end{array}$ & 0.0027 & 0.0088 & 0.0065 & 0.0079 & 0.0053 & 0.0064 & 0.0037 & 0.0060 & 0.0045 & 0.0055 & 0.0019 & 0.0024 \\
\hline
\end{tabular}

increase. We expected that stream water temperatures would lag behind the air temperature for two reasons: first, water has a higher specific heat than the atmosphere and requires more energy input per unit of mass to raise its temperature. Secondly, flow is affected by groundwater as well as precipitation. The groundwater temperature will increase over time because it approximates the mean annual air temperature, but it will do so at a slower rate because groundwater is beneath the surface and thus partly insulated from atmospheric changes. Stefan and Preud'homme (1993) found that in Midwestern surface streams driven by runoff the weekly water temperature increased by 0.86 times the weekly air temperature. However, they indicated that this value would be too high for groundwater-dominated streams. Glacial processes deposited a large amount of sand and gravel where the Muskegon River system now flows, so groundwater is a major source of discharge for the streams in the system (O'Neal 1997). Therefore, we assumed a value of 0.8 to keep the conversion rate similar but adjusted it downward slightly to reflect the difference in water source.

The classification tree models and the altered variables appropriate to each future scenario were used to make predictions for each game fish species for the years 2010, 2020, 2030, 2040, 2070, and 2100. From these predictions we determined the POs for the Muskegon River system and the five study units.

\section{Land Cover Change}

\section{Results}

According to the land transformation model, there should be substantial changes in land cover across the Muskegon watershed from 2001 through 2100 (Table 2). Across the entire system, the model predicts that both agricultural and wetland areas will decrease from
$18 \%$ of the watershed to $3 \%$. The reduction in agriculture will result in a reduction of total phosphorus across the system. Forest land will increase slightly, and urban land will increase approximately 10-fold, from $4 \%$ to $39 \%$. Flow is expected to increase as additional urban land cover prevents the infiltration of rainwater into the ground and more of it is routed directly into streams.

The specific study sites vary with respect to these general patterns. All of the study sites are expected lose most of their agricultural and wetland areas and experience increases in flow and decreases in phosphorus. However, Bigelow and Cedar creeks, which are located further downstream (closer to the city of Muskegon), are expected to lose more than half of their forested land and see their proportions of urban land increase by 67 and 74 percentage points, respectively. By contrast, the Clam and Middle Branch rivers are expected to see increases in both forest (up 12 and 23 percentage points, respectively) and urban land (up 36 and 26 percentage points).

\section{Results by Species}

Brook trout.-In the baseline scenario, a reduction in phosphorus due to the decrease in agricultural land resulted in reclassifying stream reaches from terminal node 5 (FO, 0.15) to terminal nodes $1(0.51)$ and 2 (0.84) (Figure 2a). Therefore, the model predicted that brook trout populations would increase slightly across the Muskegon system as a result of land cover change (Figure 3). However, the model also predicted that PO would decrease by 19 percentage points in Bigelow Creek (Table 3) owing to the reduction in forest and the subsequent reclassification of the stream reach from terminal node 2 (FO, 0.84) to $1(0.51)$.

A mean July water temperature value of over $19.4^{\circ} \mathrm{C}$ resulted in the classification of the streams into 
a
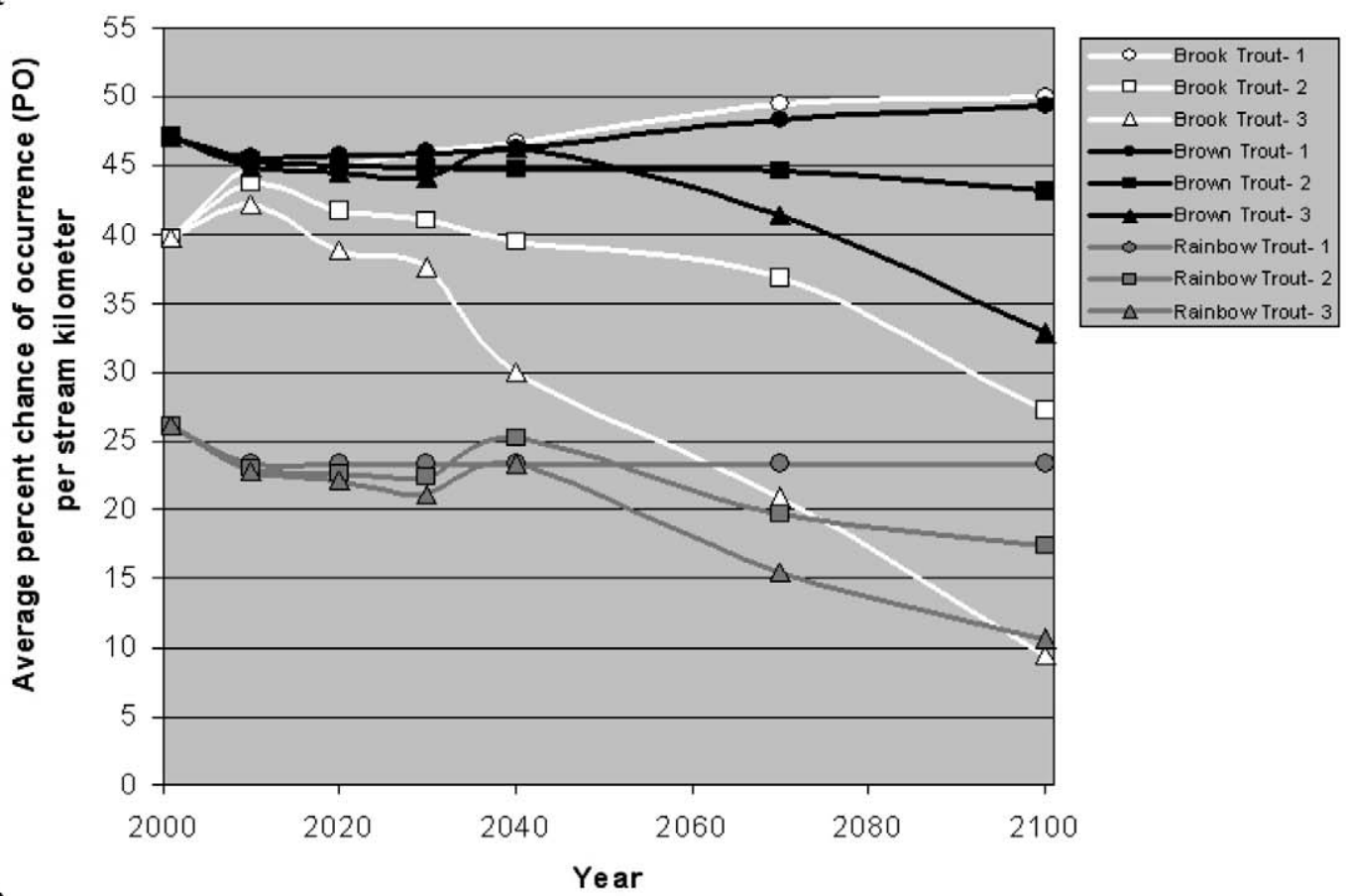

b

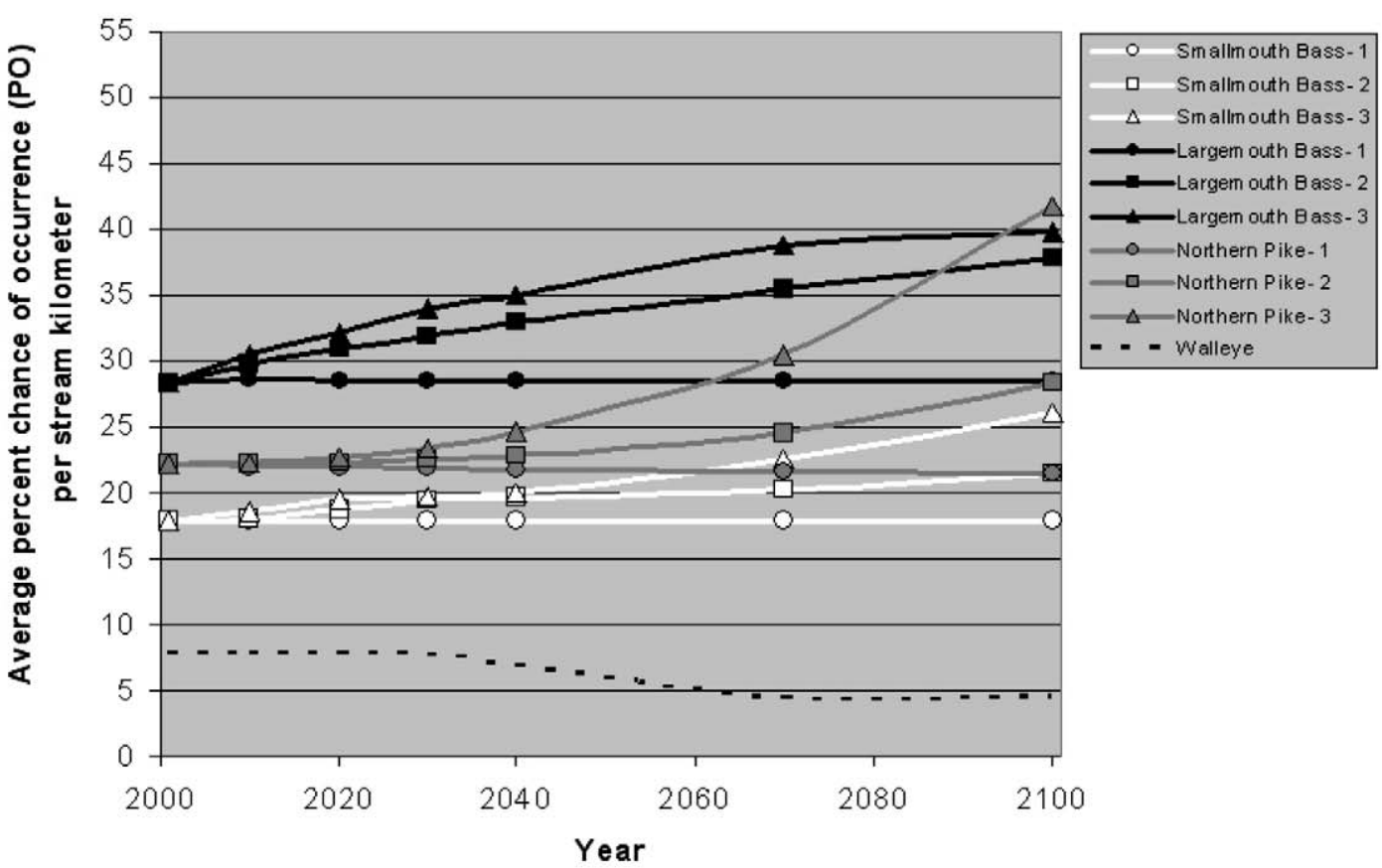

FIGURE 3.- Predictions of the average percent chance of occurrence for (a) coldwater and (b) warmwater game fish in the entire Muskegon River system under three scenarios: (1) the baseline, (2) mild temperature change, and (3) severe temperature change (see text for details). Because the walleye model does not have a temperature variable, only the baseline scenario is shown for that species. The predictions for Chinook and coho salmon are not included in the graphs because they fluctuated only slightly across the watershed. 
TABLE 3.-Percent chance of species occurrence in any stream kilometer in the Muskegon River system and five smaller study units for seven species. Three scenarios were run for each species: (1) the baseline, (2) mild temperature change, and (3) severe temperature change (see text for details). Predictions for 2020 and 2030 are not shown for simplicity.

\begin{tabular}{|c|c|c|c|c|c|c|c|c|c|c|c|c|c|c|c|c|c|c|c|}
\hline \multirow[b]{2}{*}{ Species } & \multirow[b]{2}{*}{ Year } & \multicolumn{3}{|c|}{$\begin{array}{l}\text { Muskegon } \\
\text { system }\end{array}$} & \multicolumn{3}{|c|}{$\begin{array}{c}\text { Lower } \\
\text { Muskegon } \\
\text { River }\end{array}$} & \multicolumn{3}{|c|}{$\begin{array}{c}\text { Bigelow } \\
\text { Creek }\end{array}$} & \multicolumn{3}{|c|}{$\begin{array}{l}\text { Cedar } \\
\text { Creek }\end{array}$} & \multicolumn{3}{|c|}{$\begin{array}{l}\text { Clam } \\
\text { River }\end{array}$} & \multicolumn{3}{|c|}{$\begin{array}{c}\text { Middle } \\
\text { Branch } \\
\text { River }\end{array}$} \\
\hline & & 1 & 2 & 3 & 1 & 2 & 3 & 1 & 2 & 3 & 1 & 2 & 3 & 1 & 2 & 3 & 1 & 2 & 3 \\
\hline \multirow[t]{5}{*}{ Brook trout } & 2001 & 40 & 40 & 40 & 8 & 8 & 8 & 81 & 81 & 81 & 50 & 50 & 50 & 16 & 16 & 16 & 41 & 41 & 41 \\
\hline & 2010 & 45 & 44 & 42 & 8 & 8 & 8 & 81 & 81 & 81 & 42 & 27 & 27 & 22 & 22 & 22 & 60 & 51 & 51 \\
\hline & 2040 & 47 & 40 & 30 & 8 & 8 & 8 & 81 & 81 & 81 & 45 & 37 & 45 & 18 & 14 & 18 & 60 & 35 & 25 \\
\hline & 2070 & 49 & 37 & 21 & 8 & 8 & 8 & 62 & 62 & 15 & 49 & 41 & 26 & 18 & 14 & 8 & 57 & 10 & 8 \\
\hline & 2100 & 50 & 27 & 9 & 8 & 8 & 8 & 62 & 29 & 8 & 49 & 41 & 8 & 16 & 8 & 8 & 54 & 8 & 8 \\
\hline \multirow[t]{5}{*}{ Brown trout } & 2001 & 47 & 47 & 47 & 29 & 29 & 29 & 66 & 66 & 66 & 62 & 62 & 62 & 37 & 37 & 37 & 21 & 21 & 21 \\
\hline & 2010 & 46 & 45 & 45 & 29 & 29 & 29 & 68 & 68 & 68 & 64 & 64 & 64 & 37 & 38 & 33 & 21 & 21 & 21 \\
\hline & 2040 & 46 & 45 & 46 & 29 & 29 & 29 & 68 & 68 & 68 & 64 & 56 & 55 & 37 & 33 & 30 & 21 & 21 & 21 \\
\hline & 2070 & 48 & 45 & 41 & 29 & 29 & 29 & 68 & 68 & 56 & 66 & 53 & 53 & 39 & 29 & 29 & 21 & 29 & 29 \\
\hline & 2100 & 49 & 43 & 33 & 29 & 29 & 29 & 68 & 68 & 19 & 66 & 53 & 12 & 48 & 29 & 29 & 21 & 29 & 29 \\
\hline \multirow[t]{5}{*}{ Rainbow trout } & 2001 & 26 & 26 & 26 & 50 & 50 & 50 & 69 & 69 & 69 & 68 & 68 & 68 & 20 & 20 & 20 & 18 & 18 & 18 \\
\hline & 2010 & 23 & 23 & 23 & 9 & 9 & 9 & 69 & 69 & 69 & 67 & 67 & 56 & 11 & 11 & 11 & 18 & 18 & 18 \\
\hline & 2040 & 23 & 25 & 23 & 9 & 9 & 9 & 69 & 69 & 69 & 67 & 65 & 56 & 11 & 11 & 11 & 18 & 14 & 18 \\
\hline & 2070 & 23 & 20 & 16 & 9 & 9 & 9 & 69 & 69 & 35 & 67 & 55 & 55 & 11 & 10 & 9 & 18 & 11 & 9 \\
\hline & 2100 & 23 & 17 & 11 & 9 & 9 & 9 & 69 & 39 & 9 & 67 & 55 & 9 & 11 & 9 & 9 & 18 & 9 & 9 \\
\hline \multirow[t]{5}{*}{ Coho salmon } & 2001 & 5 & 5 & 5 & 9 & 9 & 9 & 33 & 33 & 33 & 28 & 28 & 28 & 2 & 2 & 2 & 0 & 0 & 0 \\
\hline & 2010 & 5 & 5 & 5 & 9 & 9 & 9 & 33 & 33 & 26 & 28 & 28 & 28 & 2 & 2 & 2 & 1 & 1 & 1 \\
\hline & 2040 & 5 & 4 & 5 & 9 & 9 & 9 & 33 & 19 & 15 & 28 & 28 & 28 & 2 & 2 & 2 & 1 & 1 & 1 \\
\hline & 2070 & 5 & 4 & 3 & 9 & 9 & 9 & 33 & 12 & 9 & 28 & 16 & 9 & 2 & 2 & 2 & 2 & 2 & 2 \\
\hline & 2100 & 5 & 3 & 3 & 9 & 9 & 9 & 33 & 9 & 9 & 28 & 9 & 9 & 2 & 2 & 2 & 2 & 2 & 2 \\
\hline \multirow[t]{5}{*}{ Smallmouth bass } & 2001 & 18 & 18 & 18 & 81 & 81 & 81 & 8 & 8 & 8 & 8 & 8 & 8 & 47 & 47 & 47 & 8 & 8 & 8 \\
\hline & 2010 & 18 & 18 & 19 & 81 & 81 & 81 & 8 & 8 & 8 & 8 & 8 & 8 & 47 & 47 & 58 & 8 & 8 & 8 \\
\hline & 2040 & 18 & 20 & 20 & 81 & 81 & 81 & 8 & 8 & 8 & 8 & 8 & 8 & 47 & 63 & 63 & 8 & 8 & 8 \\
\hline & 2070 & 18 & 20 & 23 & 81 & 81 & 81 & 8 & 8 & 8 & 8 & 8 & 9 & 47 & 63 & 64 & 8 & 8 & 11 \\
\hline & 2100 & 18 & 22 & 26 & 81 & 81 & 81 & 8 & 8 & 19 & 8 & 9 & 9 & 47 & 64 & 66 & 8 & 9 & 14 \\
\hline \multirow[t]{5}{*}{ Largemouth bass } & 2001 & 28 & 28 & 28 & 53 & 53 & 53 & 18 & 18 & 18 & 28 & 28 & 28 & 41 & 41 & 41 & 23 & 23 & 23 \\
\hline & 2010 & 29 & 30 & 30 & 53 & 53 & 53 & 18 & 18 & 18 & 28 & 28 & 28 & 43 & 47 & 47 & 23 & 35 & 44 \\
\hline & 2040 & 29 & 33 & 35 & 53 & 53 & 53 & 18 & 18 & 18 & 28 & 28 & 28 & 42 & 46 & 46 & 23 & 49 & 57 \\
\hline & 2070 & 29 & 36 & 39 & 53 & 53 & 53 & 18 & 40 & 42 & 28 & 28 & 32 & 41 & 46 & 46 & 23 & 57 & 57 \\
\hline & 2100 & 28 & 38 & 40 & 53 & 53 & 53 & 18 & 42 & 43 & 28 & 30 & 32 & 41 & 46 & 46 & 23 & 57 & 57 \\
\hline \multirow[t]{5}{*}{ Northern pike } & 2001 & 22 & 22 & 22 & 74 & 74 & 74 & 13 & 13 & 13 & 14 & 14 & 14 & 25 & 25 & 25 & 26 & 26 & 26 \\
\hline & 2010 & 22 & 22 & 22 & 74 & 74 & 74 & 13 & 13 & 13 & 14 & 14 & 14 & 19 & 19 & 19 & 26 & 26 & 26 \\
\hline & 2040 & 22 & 23 & 25 & 74 & 74 & 74 & 13 & 13 & 13 & 14 & 14 & 16 & 19 & 19 & 37 & 26 & 26 & 26 \\
\hline & 2070 & 22 & 24 & 30 & 74 & 74 & 74 & 13 & 13 & 13 & 14 & 16 & 27 & 19 & 37 & 63 & 26 & 26 & 31 \\
\hline & 2100 & 22 & 28 & 42 & 74 & 74 & 74 & 13 & 13 & 13 & 14 & 16 & 27 & 19 & 60 & 69 & 26 & 26 & 63 \\
\hline
\end{tabular}

terminal node 6 (FO, 0.08). Therefore, in both of the temperature change scenarios, the brook trout model predicted that prevalence would be drastically reduced over the 21st century (Table 3; Figure 3). Eventually, whether the temperature change was slow or fast, the model predicted the virtual eradication of brook trout. The exception to this was Cedar Creek, which was cold enough to withstand the water temperature increase in the mild temperature change scenario (at least through 2100; Table 3). Bigelow Creek also remained below the $19.4^{\circ} \mathrm{C}$ threshold, but the expected deforestation resulted in substantial reductions in all three scenarios.

Brown trout.-The model predicted that by themselves future land cover changes would cause only minor fluctuations in the brown trout populations in the Muskegon watershed (Table 3; Figure 3). However, in the climate warming scenarios the model predicted a reduction in brown trout prevalence because the temperature in most stream reaches rose above $20.2^{\circ} \mathrm{C}$ and the predictions shifted from terminal nodes 1,2 , and 3 (FOs, 0.58, 0.34, 0.76, respectively) to terminal node $4(0.16)$ and $5(0.36)$ (Figure 2b). The brown trout in Bigelow and Cedar creeks were predicted to decline rapidly under the severe temperature change scenario as higher temperatures combined with deforestation resulted in streams being classified into terminal node 4 (FO, 0.16; Table 3). However, the streams with more than $30 \%$ forest in the watershed (terminal node 5; FO, 0.36) have some potential to retain brown trout despite the high water temperatures. Therefore, brown trout were predicted to maintain populations in the lower Muskegon, Clam, and Middle Branch rivers (Table 3).

Rainbow trout.-The rainbow trout model predicted a high FO for stream reaches with a mean July water temperature less than $19.7^{\circ} \mathrm{C}$ and without a dam 
TABLE 4.- Percent chance of species occurrence in any stream kilometer in the Muskegon system and five smaller study units for Chinook salmon and walleyes. Only the baseline scenario was run because the models did not include temperature data. Predictions for 2020 and 2030 are not shown for simplicity.

\begin{tabular}{|c|c|c|c|c|c|c|c|}
\hline Species & Year & $\begin{array}{l}\text { Muskegon } \\
\text { system }\end{array}$ & $\begin{array}{c}\text { Lower } \\
\text { Muskegon River }\end{array}$ & $\begin{array}{l}\text { Bigelow } \\
\text { Creek }\end{array}$ & $\begin{array}{l}\text { Cedar } \\
\text { Creek }\end{array}$ & $\begin{array}{l}\text { Clam } \\
\text { River }\end{array}$ & $\begin{array}{c}\text { Middle } \\
\text { Branch River }\end{array}$ \\
\hline \multirow[t]{5}{*}{ Chinook salmon } & 2001 & 6 & 40 & 39 & 22 & 0 & 0 \\
\hline & 2010 & 5 & 40 & 39 & 22 & 0 & 1 \\
\hline & 2040 & 5 & 40 & 39 & 22 & 0 & 1 \\
\hline & 2070 & 4 & 40 & 22 & 4 & 0 & 1 \\
\hline & 2100 & 3 & 40 & 4 & 4 & 0 & 1 \\
\hline \multirow[t]{5}{*}{ Walleye } & 2001 & 8 & 57 & 2 & 2 & 6 & 6 \\
\hline & 2010 & 8 & 57 & 2 & 1 & 7 & 6 \\
\hline & 2040 & 7 & 35 & 2 & 1 & 5 & 6 \\
\hline & 2070 & 4 & 26 & 2 & 2 & 5 & 5 \\
\hline & 2100 & 4 & 26 & 2 & 2 & 5 & 5 \\
\hline
\end{tabular}

blocking passage to a Great Lake (terminal node 1; FO, 0.69; Figure 2c). In 1906, Croton Dam was built on the main branch of the Muskegon River, so about threefourths of Muskegon stream reaches were disconnected from Lake Michigan throughout the years of model application. As a result, the PO for rainbow trout was around $18-20 \%$ for the streams above Croton Dam throughout the 21 st century.

Dramatic changes occurred in the streams below Croton Dam (i.e., the lower Muskegon River, Bigelow Creek, and Cedar Creek; Table 3). The predictions made under the baseline scenario indicated that the PO for rainbow trout in the lower Muskegon River would decrease by $80 \%$ by 2100 owing to reductions in the base flow caused by increased urbanization (terminal node 5; FO, 0.09). Temperature change did not affect the fish in the lower Muskegon River, as these stream reaches were already above the $19.7^{\circ} \mathrm{C}$ threshold given by the model.

In the mild temperature change scenario, rainbow trout were able to maintain a presence in Bigelow and Cedar creeks in 2100 but were on a trajectory to extirpation by 2130 . Owing to its cold water, Bigelow Creek maintained a $69 \%$ PO until 2070 in the mild temperature change scenario, but the prevalence of rainbow trout decreased rapidly after that (Table 3). In the severe temperature scenario, the rainbow trout in Cedar Creek started to decrease by 2020, stabilized until 2070, and then declined rapidly as the temperatures in most of the stream reaches rose above $19.7^{\circ} \mathrm{C}$. By 2100 , rainbow trout were almost eradicated from the Muskegon River system.

Chinook and coho salmon.-Dam location was very important for both Chinook and coho salmon: the best Chinook salmon (terminal node 2; FO, 0.39; Figure 2d) and coho salmon streams (terminal node 1; FO, 0.33; Figure 2e) were found below Croton Dam. As the fish cannot independently travel above Croton Dam, we will only discuss results for the lower Muskegon River, Bigelow Creek, and Cedar Creek.

In the baseline scenario, Chinook salmon were predicted to virtually disappear by 2100 in both Cedar and Bigelow creeks owing to the decrease of forest cover in their watersheds and the consequent switch from terminal node 2 (FO, 0.39) to terminal node 1 (0.08) (Table 4). By contrast, the lower Muskegon River was predicted to maintain a good Chinook salmon population throughout the forecast years.

Future land cover changes were not predicted to affect coho salmon. However, an increase in water temperature to above $18.0^{\circ} \mathrm{C}$ reclassified the streams below Croton Dam from terminal node 1 (FO, 0.33) to terminal node 2 (0.09). Bigelow and Cedar Creeks were predicted to lose nearly all potential for coho salmon by 2100 under both temperature increase scenarios (Table 3).

Smallmouth and largemouth bass.-While variables affected by land cover change (total phosphorus and the $10 \%$ exceedance flow yield) were included in the smallmouth and largemouth bass models, they did not change enough over the years of model application to alter the predicted occurrence of these species. Therefore, under the baseline scenario the models did not predict changes in the distribution of these two species (Figure 3). Smallmouth bass were predicted to be found in warm, large rivers such as the lower Muskegon River and in a few reaches of the Clam River (Table 3; Figure 2f), while largemouth bass was predicted to be in those streams as well as in cool- and warmwater rivers $\left(>18.9^{\circ} \mathrm{C}\right)$ within $20 \mathrm{~km}$ of ponds or lakes (Table 3; Figure 2g).

Under the climate warming scenarios, smallmouth bass were able to move into smaller streams that were formerly too cold to support them. Across the watershed, the PO for smallmouth bass was predicted to increase 8 percentage points by 2100 under the 
severe temperature change scenario (Table 3 ). It was predicted to increase slightly in the colder streams (Bigelow Creek and the Middle Branch River) by 2100 but to have a more substantial increase of 19 percentage points in the Clam River (Table 3). If the models were run through 2200 with the same rate of temperature increase, the predictions would show smallmouth bass distributed throughout the watershed.

By 2100 , the model predicted across-the-watershed increases in the PO of largemouth bass of 12 percentage points in the severe temperature change scenario and $10 \%$ in the mild change scenario (Figure 3 ). The model predicted approximately 25 -percentagepoint increases in the probability of largemouth bass being in Bigelow Creek and the Middle Branch River and a very small increase for Cedar Creek (Table 3). The probability of their being in the Clam and lower Muskegon rivers did not increase with temperature since these streams already had a mean July water temperature greater than $18.9^{\circ} \mathrm{C}$ (the temperature threshold identified by the largemouth bass model; Figure 2g) in 2001.

Northern pike.-The northern pike model had a high FO in streams with a mean July water temperature greater than $21.9^{\circ} \mathrm{C}$ (terminal node 6; FO, 0.74; Figure $2 \mathrm{~h}$ ). As the Muskegon River system consists largely of cold- and coolwater, in 2001 the only stream reaches with high northern pike POs were in the lower Muskegon River (Table 3). The model predicted no changes in northern pike distributions under the baseline scenario (Figure 3).

However, water temperature increases in the severe temperature change scenario caused the northern pike PO to increase by $20 \%$ across the entire Muskegon River system (Figure 3). The effect on individual streams varied, however. The PO value in the lower Muskegon River remained unchanged because the temperature there was already above the $21.9^{\circ} \mathrm{C}$ threshold given by the classification model. That in Bigelow Creek remained unchanged owing to that water body's very low water temperature, and that in Cedar Creek only increased by 15 percentage points in the severe temperature change scenario. The Clam River, however, had mean July water temperatures very close to $21.9^{\circ} \mathrm{C}$, and increases caused an increase of nearly $50 \%$ in the PO for northern pike in both climate warming scenarios. The Middle Branch River, which has a water temperature between those of the Clam River and Cedar Creek, experienced an increase of 37 percentage points by 2100 in the severe temperature change scenario (Table 3 ).

Walleye.-The walleye model predicted an FO of 0.57 in streams with a catchment area greater than 656 $\mathrm{km}$ and less than $9 \%$ urbanization (terminal node 4;
Figure 2i). In 2001, the main branch of the Muskegon River was the only stream reach that met this criterion. However, owing to expected urban expansion, urban land cover was predicted to be more than $9 \%$ in the watershed of the lower Muskegon River by 2040 and in the rest of the main-stem Muskegon River (above and below Croton Dam) by 2070. This change reclassified these streams from terminal node 4 (FO, $0.57)$ to terminal node $5(0.26)$, halving the predicted prevalence of walleye by 2070 (Table 4; Figure 3).

\section{Discussion}

\section{Model Application}

Across the Muskegon River system, the classification tree models predicted substantial changes in the habitat ranges of game fish by 2100 . The predominant outcome was a change from a system dominated by coldwater fish to one dominated by cool- and warmwater fish. In the land cover change scenarios only, the models predicted declines in walleyes and Chinook salmon across the system. In the climate change scenarios, they predicted declines in coho salmon and brook, brown, and rainbow trout. This pattern agrees with the results of a variety of studies examining how coldwater fish will be affected by climate change (Meisner 1990; Eaton and Scheller 1996; Jager et al. 1999; Stefan et al. 2001; Flebbe 2006). The models predict slight increases in smallmouth bass, larger increases in largemouth bass, and larger yet increases in northern pike. The highest decline detected was a $90 \%$ reduction in the probability that brook trout would occur in Bigelow Creek, while the greatest increase was a $276 \%$ increase in the probability that northern pike would occur in the Middle Branch River.

There was spatial variation within the Muskegon River system; some streams were predicted to change more and others less. Bigelow and Cedar creeks were both projected to lose much of their forested lands and gain urban cover. Combined with the severe temperature increase, this resulted in Bigelow Creek's losing virtually all of its brook, brown, and rainbow trout and Chinook and coho salmon. Similarly, Stranko et al. (2008) found that Maryland streams with more than $4 \%$ urbanization almost never held brook trout unless that water was consistently at a cold temperature. Bigelow Creek warmed enough to gain largemouth bass but not northern pike. Cedar Creek was predicted to respond like Bigelow Creek but also gained northern pike owing to its higher initial temperatures. The mild temperature change scenario also showed these patterns, although the changes were predicted to occur more gradually.

The Middle Branch and Clam rivers were predicted to lose brook trout because of water temperature 
increases but were expected to maintain their populations of brown trout, as much of their watersheds' forest land cover was maintained through 2100 . Both of these rivers were expected to gain northern pike, smallmouth bass, and largemouth bass. The lower Muskegon River was projected to see declines in walleyes owing to continued urbanization and declines in Chinook salmon owing to deforestation caused by urbanization. Temperature changes were not predicted to affect the lower Muskegon River because it was already above the temperature thresholds for coldwater species given by the models.

Overall, temperature changes were predicted to cause much greater shifts in fish occurrence than were land cover changes. Typically, the water temperature variable was brought into the classification tree models earlier in model formulation than land cover, influencing a greater number of observations and indicating its greater relative importance. However, for all of the species modeled except brook trout, it was ultimately the combination of water temperature and land cover that determined the percent chance of occurrence. Brook trout were the exception in that the model showed that high temperature alone would prevent species occurrence.

\section{Using Land Cover as a Management Strategy}

Altering water temperature and land cover is difficult, but managers do have the ability to affect land use practices so as to offset the trends predicted by this study. If preserving coldwater habitat is the goal, increasing forest size, limiting urban areas, and decreasing agricultural land would increase the potential for coldwater fish to live in the Muskegon River system. In addition, the phosphorus, flow, and stream power variables in our models are affected by urbanization and agricultural practices (Brenden et al. 2006; Steen et al. 2008) that hopefully can be influenced by land development policies.

Changes in the habitat variables highlighted by our models do not guarantee that the species can live in the manipulated area, but at least they increase the potential for species establishment or maintenance. For example, rainbow trout are found in $21 \%$ of Michigan streams that have an average July water temperature less than $19.7^{\circ} \mathrm{C}$, are above a dam, have a $90 \%$ exceedance flow yield greater than 0.0043 , and have a watershed with more than $20 \%$ agriculture. Reducing the percentage of agriculture in the watershed to less than $20 \%$ would place those streams in terminal node 3 , for which the chance of rainbow trout presence is $39 \%$. According to the model, therefore, the likelihood of rainbow trout being present would almost double.

Playing "what-if" games with the models in this manner can help managers to develop management strategies. Brown trout are only found in $16 \%$ of the streams with a temperature above $20.2^{\circ} \mathrm{C}$ when the watershed has less than $31 \%$ forest. However, they are found in $36 \%$ of such streams when the amount of forest is greater than $31 \%$. Increasing the amount of forest to more than $31 \%$ would double the chance of finding brown trout in cool- and warmwater streams. Similarly, increasing the amount of forest to more than $40 \%$ would quadruple the chance of finding Chinook salmon, and increasing it to more than $50 \%$ would increase the chance of finding brook trout by $33 \%$ (assuming that the other habitat requirements on the classification tree are met). The benefits of forested land on stream fish has long been recognized by researchers (Talmage et al. 2002; Meador and Goldstein 2003; Roy et al. 2006; Barker et al. 2006).

Walleyes are only found in $26 \%$ of large streams (those with catchment areas $>650 \mathrm{~km}^{2}$ ) when urbanization is greater than $9 \%$, but they are found in $57 \%$ of large streams when urbanization is less than 9\%. Thus, keeping urbanization below $9 \%$ is essential for maintaining walleyes. This threshold is very similar to those found by other studies that have looked at urbanization and fish communities (Wang et al. 2001; Snyder et al. 2003; Riseng et al. 2006).

Chinook salmon, coho salmon, and rainbow trout are far more likely to be found in streams directly connected to the Great Lakes than in streams separated from those lakes by a dam. A continued emphasis on removing dams, especially those that are located near the Great Lakes, is important for managers who are interested in maintaining and expanding salmon populations. Dam removal will also keep water temperatures lower.

\section{Justifying the Use of Classification Trees}

A conceptual issue that must be addressed is how these models, which are built on present-day habitat data, can still be accurate when using future habitat data. To address this issue, we must discuss how classification trees are built and their ecological significance.

Classification trees are built through brute-force computer algorithms. For every variable, the computer divides the data into two groups and compares the frequency of the target classes in both groups. It does this for every possible split, splitting the data into two groups, one observation at a time. The final split depends on the exact splitting rule the user picks, but in general it is the one for which the two groups have the lowest possible amount of overlap for the predicted classes. The computer cannot possibly be using ecological mechanisms to determine the shape of the 
tree; the procedure is simply a pattern processor and has no ability to understand what is really happening in nature.

Despite being an automated process, this algorithm produces a tree that is both ecologically meaningful and accurate. The models used in this study are able to accurately predict the presence or absence of a fish species in a stream about $75 \%$ of the time (Steen et al. 2008). For most of the nodes in the trees (though certainly not all), the variable chosen and the split made in that variable are consistent with our understanding of that species' physiological needs (e.g., temperature) or usual location in the landscape (e.g., distance from a lake).

Conceptually, the classification tree treats species as if they were constrained to live within certain variable ranges. Every split within the tree marks either a lower or upper bound of the range for a particular habitat variable. Usually, only one end of the range is recorded in the tree. For example, the habitat suitability index for brook trout shows that the species is constrained to temperatures between $0^{\circ} \mathrm{C}$ and $24^{\circ} \mathrm{C}$ (Raleigh 1982). Our brook trout model created a cut value at $19.4^{\circ} \mathrm{C}$, showing the upper endpoint of the temperature range. However, because our data for stream temperatures never go below about $15^{\circ} \mathrm{C}$, the model does not show the lower boundary at all. For land cover data, a split creates a range of habitat values from that split value to $100 \%$ or $0 \%$. For any variable, the habitat range created from a single split goes from the split value to either the minimum or maximum value of that variable in the data set. The exception to this would be when the model includes two or more splits of a single variable, which would narrow the habitat range to a portion of the data. Since a classification tree model identifies a series of habitat ranges, the pieces of the tree are conceptually very similar to a quantitative version of Hutchinson's (1957) $n$-dimensional niche-the habitat space in which a species is able to maintain a population. For example, a terminal node classified as "present" with three habitat variable splits above it would represent a potential three-dimensional habitat space.

As each of the classification models used in this study gives an estimate of a niche, we can conclude that they will accurately predict fish distributions in future years as long as the niche does not change and the expected changes in the predictor variables match the habitat changes in the real world.

\section{Model Limitations}

As with all models, there are limitations to the predictions that must be recognized. The classification tree technique does not use continuous predictors but inherently assumes thresholds. Threshold effects-in particular, the effects of urbanization on stream biology-have been recognized in previous studies (Wang et al. 2001), but thresholds are influenced by the idiosyncrasies of the training set, so that a study's thresholds would be slightly different with different data or important thresholds would be missing from the model altogether. A specific example of this problem can be found in our brown trout model's prediction that that species will be found in $36 \%$ of the streams with a water temperature above $20.2^{\circ} \mathrm{C}$ and a watershed with more than $30 \%$ forest. Obviously, if the water temperature became high enough that the fish could no longer obtain oxygen, the amount of forested land would not matter. In this case, a threshold that should have been in the model was not included because those warmer streams were not included in the training data. A good rule to follow is to remember that the exact value of the splits in the model is not as important as the general trends that they reflect and that there may be important pieces left out owing to data limitations.

There are also some limitations in our data that could limit the accuracy of the results. First, we made the assumption that water temperature increases linearly over time at a particular rate. This assumption was derived from a study that examined a runoff-driven system (Stefan and Preud'homme 1993) rather than a groundwater system like the Muskegon River watershed. Future studies, however, may obtain more accurate results by modeling the water temperature rate change explicitly rather than making an assumption about it.

Second, in the two global warming scenarios, we only altered the mean annual air and stream temperatures. Climate change, however, is expected to affect many of the model's input variables, such as total phosphorus and stream exceedance flows, that rely on water quantity and quality (Regier and Meisner 1990). It is expected that changes in water quality and quantity will affect future fish distributions, but these changes are difficult to predict and were not included in our models. Because the changes in water quantity and quality due to climate change are generally thought to be negative for fish (Schindler 2001), our predictions may be best-case scenarios.

Third, all of the models in this study were built with present-day temperature data. In these models, warmwater fish typically have a lower bound on temperature but not an upper bound; for example, smallmouth bass are unlikely to be found in water less than $21.3^{\circ} \mathrm{C}$, but there is no upper bound for them. In 2001, the maximum mean July water temperature of Michigan streams was around $25^{\circ} \mathrm{C}$, which is below the maximum temperature that a smallmouth bass can 
tolerate (approximately $32^{\circ} \mathrm{C}$; Edwards et al. 1983), and owing to the way in which classification trees are built it was impossible to have an upper bound on temperature in the model. Therefore, in future predictions, smallmouth bass could be predicted to live in streams no matter how warm those streams became; the models lose realism when used in conjunction with water temperatures outside the range with which they were created. Having upper temperature bounds for warmwater species may be more realistic for future scenarios, in which stream temperatures could become quite hot.

\section{Conclusion}

The classification tree models created in Steen et al. (2008) and applied to a relevant problem in this study represent a useful and logical tool that other researchers and managers can develop for the areas in which they are interested. Furthermore, the models give quantitative estimates of species niches that can serve as the basis for future studies.

This study is unique because it predicts what will happen to fish communities based on both climate change and future alterations in land cover. The results indicate that the Muskegon River system will shift from coldwater fish communities to warmwater communities during the $21 \mathrm{st}$ century given the predicted temperature increases and business-as-usual land development. Predictions such as this are useful because they provide both a warning and an incentive for action. The fish models indicated that landscapescale habitat and disturbances can have both positive and negative effects on particular species; the clear task for managers is to restore and maintain stream and watershed habitat so as to maximize species potential and minimize species risk.

\section{Acknowledgments}

This study was funded by the U.S. Geological Survey's Gap Analysis Program, with additional inkind support from the Institute for Fisheries Research, Michigan Department of Natural Resources (MDNR). The development of the GIS framework was funded in part through a STAR grant from the U.S. Environmental Protection Agency's National Center for Environmental Research. The GIS data were processed by Great Lakes Aquatic GAP members A. Cooper, S. Aichele, E. Bissell, and J. Stewart. Special thanks to K. Wehrly (MDNR) and A. Rasolofoson for providing and organizing the fish data and to P. Seelbach, G. Kling, and three anonymous reviewers for suggestions that greatly improved the manuscript. We also thank B. Pijanowski and his team for simulating future land cover changes in the Muskegon River watershed. C.
Riseng and S. David gave wise input regarding the streams and fish of the watershed. Any use of trade, product, or firm names is for descriptive purposes only and does not imply endorsement by the U.S. Government. This article is contribution 1565 of the U.S. Geological Survey Great Lakes Science Center.

\section{References}

Barker, L. S., G. K. Felton, and E. Russek-Cohen. 2006. Use of Maryland biological stream survey data to determine effects of agricultural riparian buffers on measures of biological stream health. Environmental Monitoring and Assessment 117:1-19.

Booth, D., and C. Jackson. 1997. Urbanization of aquatic systems: degradation thresholds, storm water detection, and the limits of migration. Journal of the American Water Resources Association 33:1077-1090.

Breiman, L. F., R. Olshen, and C. Stone. 1984. Classification and regression trees. Chapman and Hall, New York.

Brenden, T. O., R. D. Clark, A. R. Cooper, P. W. Seelbach, L. Wang, S. Aichele, E. G. Bissell, and J. S. Stewart. 2006. A GIS framework for collecting, managing, and analyzing multiscale landscape variables across large regions for river conservation and management. Pages 49-74 in R. M. Hughes, L. Wang, and P. W. Seelbach, editors. Landscape influences on stream habitat and biological assemblages. American Fisheries Society, Symposium 48, Bethesda, Maryland.

Eaton, J. G., and R. M. Scheller. 1996. Effects of climate warming on fish thermal habitat in streams of the United States. Limnology and Oceanography 41.

Edwards, E. A., G. Gebhart, and O. E. Maughan. 1983. Habitat suitability information: smallmouth bass. U.S. Fish and Wildlife Service FWS/OBS-82/10.36.

Flebbe, P. A., L. D. Roghair, and J. L. Bruggink. 2006. Spatial modeling to project southern Appalachian trout distribution in a warmer climate. Transactions of the American Fisheries Society $135: 1371-1382$.

Hanchin, P. A., R. P. O’Neal, R. D. Clark, and R. N. Lockwood. 2007. The walleye population and fishery of the Muskegon Lake system, Muskegon and Newaygo counties, Michigan, in 2002. Michigan Department of Natural Resources, Special Report 40, Ann Arbor.

Hutchinson, G. E. 1957. Concluding remarks. Cold Spring Harbor Symposium on Quantitative Biology 22:415427.

Klein, R. 1979. Urbanization and stream quality impairment. Water Resources Bulletin 15:948-963.

Jager, H. W. E., W. Van Winkle, and B. D. Holcomb. 1999. Would hydrologic climate changes in Sierra Nevada streams influence trout persistence? Transactions of the American Fisheries Society 128:222-240.

MCGI (Michigan Center for Geographic Information). 2008. Land cover 2001 geographic theme: land cover/use. Available: www.michigan.gov/cgi. (March 2008.)

Meador, M. R., and R. M. Goldstein. 2003. Assessing water quality at large geographic scales: relations among land use, water physicochemistry, riparian condition, and fish community structure. Environmental Management 31:504-517.

Meisner, J. D. 1990. Potential loss of thermal habitat for brook trout, due to climatic warming, in two southern Ontario streams. Transactions of the American Fisheries Society 119:282-291. 
Miltner, R. J., D. White, and C. Yoder. 2004. The biotic integrity of streams in urban and suburbanizing landscapes. Landscape and Urban Planning 69:87-100.

Morgan, R., and S. Cushman. 2005. Urbanization effects on stream fish assemblages in Maryland, USA. Journal of the North American Benthological Society 24:643-655.

National Assessment Synthesis Team. 2001. Climate change impacts on the United States: the potential consequences of climate variability and change. Report for the U.S. Global Change Research Program. Cambridge University Press, Cambridge, UK.

O’Neal, R. P. 1997. Muskegon River watershed assessment. Michigan Department of Natural Resources, Special Report 19, Lansing.

Pijanowski, B. C., D. G. Brown, G. Manik, and B. Shellito. 2002a. Using artificial neural networks and GIS to forecast land use changes: a land transformation model. Computers, Environment, and Urban Systems 26(6): 553-575.

Pijanowski, B. C., S. Pithadia, K. Alexandridis, and B. Shellito. 2005. Forecasting large-scale land use change with GIS and neural networks. International Journal of Geographic Information Science 19:197-215.

Pijanowski, B. C., B. Shellito, and S. Pithadia. 2002b. Using artificial neural networks, geographic information systems, and remote sensing to model urban sprawl in coastal watersheds along eastern Lake Michigan. Lakes and Reservoirs 7:271-285.

Raleigh, R. F. 1982. Habitat suitability index models: brook trout. U.S. Fish and Wildlife Service FWS/OBS-82/ 10.24 .

Regier, H. A., and J. D. Meisner. 1990. Anticipated effects of climate change on freshwater fishes and their habitat. Fisheries 15(6):10-15.

Riseng, C. M., M. J. Wiley, R. J. Stevenson, T. G. Zorn, and P. W. Seelbach. 2006. Comparison of coarse- versus fine-scale sampling on statistical modeling of landscape effects and assessment of fish assemblages of the Muskegon River, Michigan. Pages 555-575 in R. M. Hughes, L. Wang, and P. W. Seelbach, editors. Influence of landscapes on stream habitats and biological assemblages. American Fisheries Society, Symposium 48, Bethesda, Maryland.

Roy, A. H., M. C. Freeman, B. J. Freeman, S. J. Wenger, J. L. Meyer, and W. E. Ensign. 2006. Importance of riparian forests in urban catchments contingent on sediment and hydrologic regimes. Environmental Management 37:523-539.

Schindler, D. W. 2001. The cumulative effects of climate warming and other human stresses on Canadian freshwaters in the new millennium. Canadian Journal of Fisheries and Aquatic Sciences 58:18-29.

Scott, J. B., C. R. Stewart, and Q. J. Stober. 1986. Effect of urban development on fish population dynamics in Kelsey Creek, Washington. Transactions of the American Fisheries Society 115:555-567.

Seelbach, P. W., and M. J. Wiley. 1997. Overview of the Michigan Rivers Inventory (MRI) project. Michigan Department of Natural Resources, Fisheries Technical Report 97-3, Ann Arbor.

Seelbach, P. W., and M. J. Wiley. 2005. An initial landscapebased system for ecological assessment of Lake Michigan tributaries. Pages 559-581 in T. Edsall and M.
Munawar, editors. State of Lake Michigan: ecology, health, and management. Ecovision World, Monograph Series, Burlington, Ontario.

Snyder, C. D., J. A. Young, R. Villella, and D. P. Lemarie. 2003. Influences of upland and riparian land use patterns on stream biotic integrity. Landscape Ecology 18:647664.

Steen, P. J., T. G. Zorn, P. W. Seelbach, and J. S. Schaeffer. 2008. Classification tree models for predicting distributions of Michigan stream fish from landscape variables. Transactions of the American Fisheries Society 137:976996.

Stefan, H. G., and E. B. Preud'homme. 1993. Stream temperature estimation from air temperature. Water Resources Bulletin 29:27-45.

Stefan, H. G., X. Fang, and J. G. Eaton. 2001. Simulated fish habitat changes in North America lakes in response to projected climate warming. Transactions of the American Fisheries Society 130:459-477.

Stranko, S. A., R. H. Hilderbrand, R. P. Morgan II, M. W. Staley, A. J. Beck, A. Roseberry-Lincoln, E. S. Perry, and P. T. Jacobson. 2008. Brook trout declines with land cover and temperature changes in Maryland. North American Journal of Fisheries Management 28:12231232.

Tabit, C. R., and G. M. Johnson. 2002. Influence of urbanization on the distribution of fishes in a southeastern upper Piedmont drainage. Southeastern Naturalist $1: 253-268$.

Talmage, P. J., J. A. Perry, and R. M. Goldstein. 2002. Relation of instream habitat and physical conditions to fish communities of agricultural streams in the northern Midwest. North American Journal of Fisheries Management 22:825-833.

Trout Unlimited. 2008. Michigan's blue ribbon trout streams. Available: www.trailstotrout.com/blueribbon.html. (March 2008.)

Walsh, C., A. Roy, J. Feminella, P. Cottingham, P. Groffman, and R. Morgan. 2005. The urban stream syndrome: current knowledge and the search for a cure. Journal of the North American Benthological Society 24:706-723.

Wang, L., J. Lyons, and P. Kanehl. 2001. Impacts of urbanization on stream habitat and fish across multiple spatial scales. Environmental Management 2001:255266.

Wang, L., J. Lyons, and P. Kanehl. 2003a. Impacts of urban land cover on trout streams in Wisconsin and Minnesota. Transactions of the American Fisheries Society 132:825839.

Wang, L., J. Lyons, P. W. Rasmussen, P. W. Seelbach, T. Simon, M. J. Wiley, P. Kanehl, E. Baker, S. Niemela, and P. M. Stewart. 2003b. Watershed, reach, and riparian influences on stream fish assemblages in the Northern Lakes and Forest Ecoregion, USA. Canadian Journal of Fisheries and Aquatic Sciences 60:491-505.

Weaver, L. A., and G. C. Garman. 1994. Urbanization of a watershed and historical changes in a stream fish assemblage. Transactions of the American Fisheries Society 123:162-172.

Zimmerman, J. K. H., B. Vondracek, and J. Westra. 2003 Agricultural land use effects on sediment loading and fish assemblages in two Minnesota (USA) watersheds. Environmental Management 32:93-105. 